\title{
Designing Passive Harmonic Filter of Electric Propulsion System on Tanker Ship
}

\author{
Indra Ranu Kusuma ${ }^{1,}$ Semin $^{2}$, Badrus Zaman ${ }^{3}$, Faisal Muhammad Satrio ${ }^{4}$,
}

\begin{abstract}
Harmonic is a frequency defect that have some negative effect to the electrical network system. In a ship, electrical network system are interconnected to each other to another electrical consumer device. The effect will impact all the device that connected to the electrical network system. This can be reducing the consumer devices reliability. This research analyzed and simulate the effect of harmonic when there is no harmonic filter condition and with a passive harmonic filter for each operating condition on this ship. This research also includes the comparison diagram between no filter and with a passive harmonic filter condition, and some simulation report from the software. The research results were VTHD value are need to be comply with the classification standards and rules. Passive harmonic filter can reduce the VTHD value by reducing a specific harmonic order and the impact from reducing specific harmonic order can reduce the other harmonic order. Besides that, passive harmonic filter also can gain a higher power factor (PF) value.
\end{abstract}

Keywords — total harmonic distortion, harmonic load flow analysis, passive filter, variable frequency drive

\section{INTRODUCTION}

$\mathrm{E}$ lectric propulsion system is applied in this research by using a three-phase induction motor as a replacement for conventional propulsion systems. However, in its application, there is interference on frequency of the electricity generated by the electric propulsion system. The quality and security of its voltage supply is crucial to the safety of any marine vessel. With the increasing use of AC and DC electric drives for applications such as electric propulsion, this has become an even greater issue. Electric propulsion provides significant benefits, such as lower running costs, less maintenance, reduced manpower, greater redundancy, lower emissions, improved maneuverability (with podded or azimuth type propulsors) and increased cargo carrying capabilities. But by drawing current in a nonlinear or non-sinusoidal manner, electric propulsion can introduce excessive levels of both current and voltage harmonics.[1]

One of them is frequency defects or harmonic due to the use of power electronic converter. Electronic power converter has functions to control the speed of threephase induction motor. As a result of frequency defects or harmonic itself could damage equipment that uses electrical energy that is connected directly to the electrical system on board. The input current to a static power converter has, in general, a high harmonic content due to the wav the current is switched (chopped)from phase to phase. Harmonic currents are important because

Indra Ranu Kusuma, Department of Marine Engineering, Institut Teknologi Sepuluh Nopember, Surabaya 60111, Indonesia, Email : irkusuma97@gmail.com

Semin, Department of Marine Engineering, Institut Teknologi Sepuluh Nopember, Surabaya 60111, Indonesia, Email : seminits@yahoo.com

M. Badrus Zaman, Department of Marine Engineering, Institut Teknologi Sepuluh Nopember, Surabaya 60111, Indonesia, Email : drus_zaman@yahoo.com

Faisal Muhammad Satrio, Department of Marine Engineering, Institut Teknologi Sepuluh Nopember, Surabaya 60111, Indonesia, Email : faisal.m.str@gmail.com they cause distortion of the supply voltage waveform which may result in the malfunction and additional heating of other equipment connected to the supply system.

To reduce the problem of defective frequency wave or harmonic, one of them can be solved by installing a passive harmonic filter. Passive harmonic filter serves to repair defects caused waves of components or other variables that could disrupt the working frequency.

The passive harmonic filter design can overcome the problem of frequency wave defects that caused from using power electronic converters that are used to control the speed of three-phase induction motor in the propulsion system on board, then some induction motor load (e.g. exhaust and supply fan), and another intermittent load. The benefits of this research are the data that have been obtained can be used as a reference in developing the Electric Propulsion System on ship and a design of the Passive Harmonic Filter for Electric Propulsion System.

This research is using a ship design based on a ship that have a length overall (LOA) below $70 \mathrm{~m}$ because this kind of ship are not complex and more convenient with its technical specification that will be established on software to do a straightforward, and easy to understand simulation.

\section{LITERATURE REVIEW}

Many literatures about harmonics have shown that harmonics have many technical impact and effects to all the devices that connected to the electrical network system. Overloads, distortion, disturbances, reduced lifetime and so on are the effects of the harmonics. [2][3]

Generally harmonic frequencies are integer multiples (e.g. 3, 5, 7, 11, 13, 15, etc.) of the fundamental (supply) frequency. The particular shape of the resulting supply voltage will depend on harmonic currents causing additional harmonic voltages in the supply reactance (inductive and/or capacitive). [4]

The harmonic value are limited due to the requirements from the standards from classification society. In this research, the harmonic limit from 
classification rules that used shall not exceed $5 \%$ of total voltage harmonic distortion (VTHD). [5]

ETAP $^{\circledR}$ Software has been used to analyze and simulate the implementation of the electrical network system on a ship. The simulation will show a different value when before and after implementing a passive harmonic filter. Figure 1 shows waveform of harmonic analysis. [6] harmonic order was not exactly the value of its harmonic frequency integer (e.g. 5th order harmonic value are not exactly 5). [8]

\section{DESIGNING PASSIVE HARMONIC FILTER WITH ETAP ${ }^{\circledR}$ SOFTWARE}

\section{A. Simulation of Ship Electrical Network System}

The electrical network that will be established on

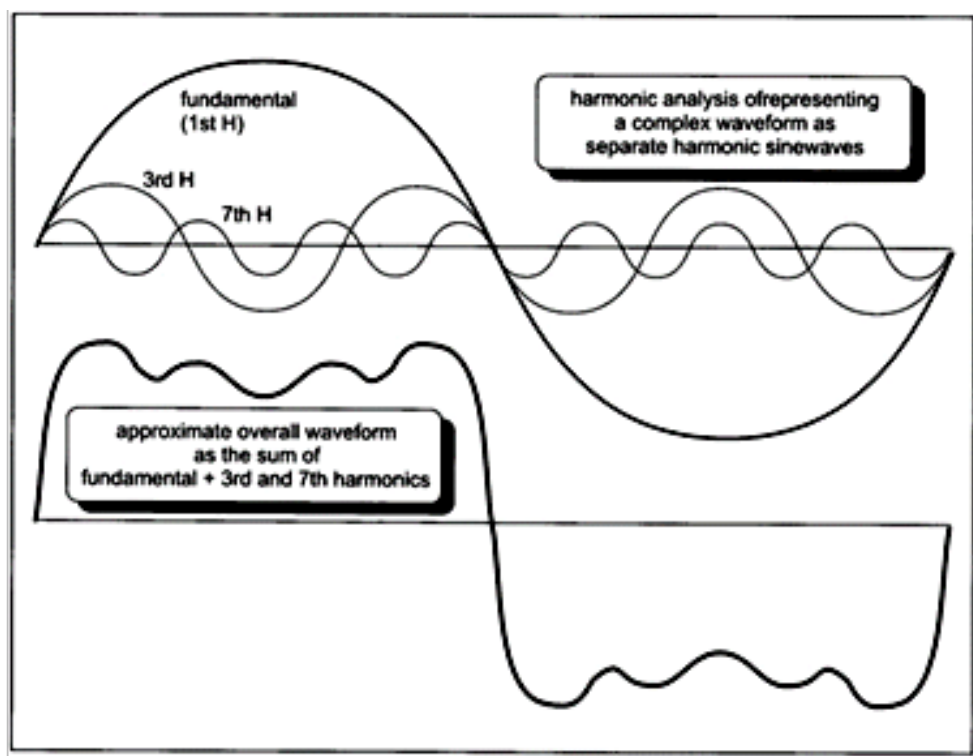

Figure 1. Harmonic analysis waveforms. [4]

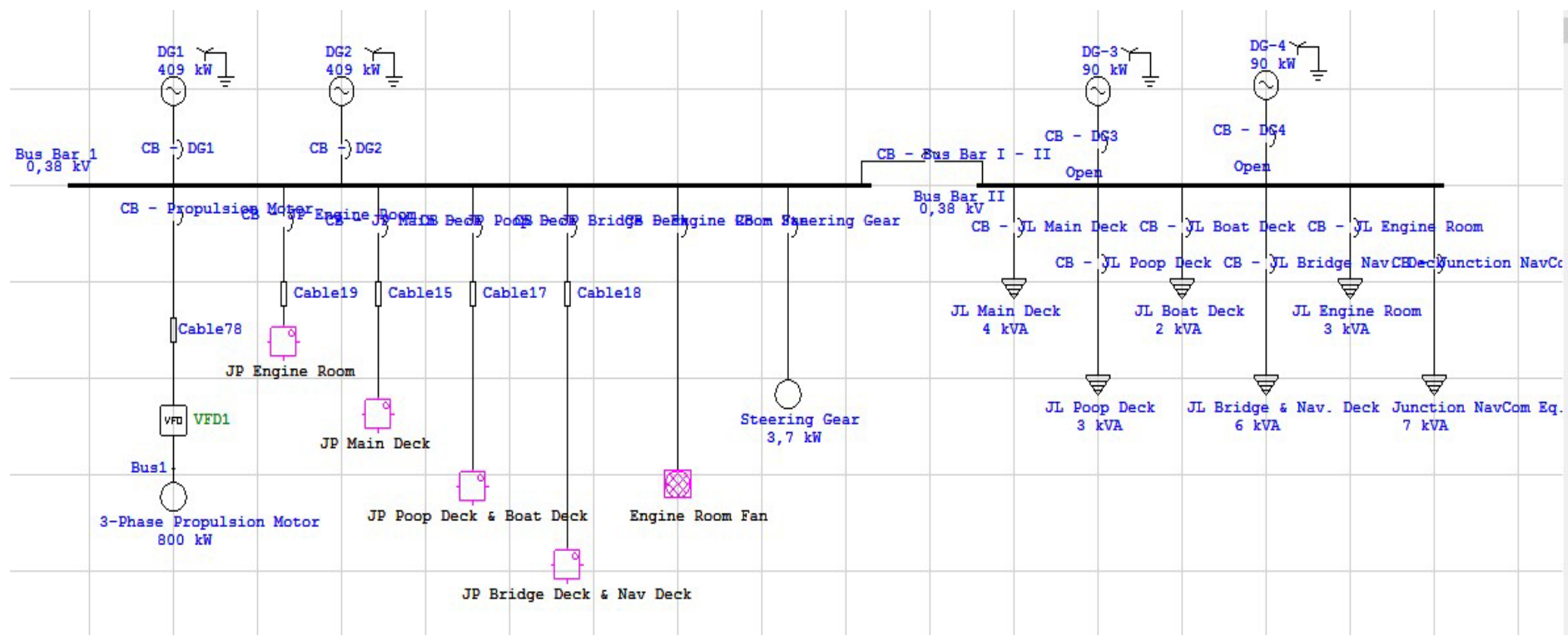

Figure 2. MT. BUMI ETAM One Line Diagram

Passive filter is a series of parallel or in series between the components of the inductor ( $\mathrm{L}$ ) and capacitor (C). The filter circuit can be tuned to a specific frequency where the impedance of the inductor to be equal to the impedance of the capacitor. The effectiveness of filters work is determined by changes in electrical network impedance, and accurate study are required prior to filter installation. [7]

There are 6 types here are 6 types of harmonic filter that provided by ETAP $^{\circledR}$ Software. But only the singletuned harmonic filter can be used for specific harmonic orders. This will have an advantage to minimized the harmonic distortion to meet rules standard. But the
ETAP software are collected from Main Switchboard data from MT. BUMI ETAM ship design technical specification. The data includes each of junction power and junction load of each deck.

Figure 2 shows the ship electrical network system simulation which was established on ETAP $^{\circledR}$. By using this software, we could obtain harmonic load flow and carry out to analyze harmonic value, including total current and voltage harmonic distortion and all aspect related load flow and harmonic analysis. 

ETAM;

Here is the principal dimension of MT. BUMI

- Name : MT. BUMI ETAM

- Type : Product Oil Tanker

- GT : 1170 ton

- Lpp : $66 \mathrm{~m}$

- Lwl : 67,98 m

- B : $12 \mathrm{~m}$

- $\mathrm{H}: 4,9 \mathrm{~m}$

- $\mathrm{T}: 4,3 \mathrm{~m}$

- $\mathrm{Cb}: 0,6966$

- Vs : 11 knots

- Radius : $200 \mathrm{mil}$

- $\rho$ water : 1,025 ton/m3

- Route : Balikpapan - Jakarta did the harmonic happen on the electrical network. The report will show if there is any harmonic value that over the limit that already set. The limit are set to 5\% according to DNV GL Rules standards. [5]

After getting the result of simulation, this first result data are not equipped with a harmonic filter. So, the harmonic value must be have a high value due to the use of variable frequency drive. The next stage after designing and installing passive harmonic filter, a simulation have to be done to know the result after applying a passive harmonic filter with a harmonic value that occur in the ship. This data will be compared by using a graph to identify the harmonic value of each bus and branch in before and after installing the passive harmonic filter. The simulation report are shown in Table 1 and Table 2.

In the other condition; cargo handling and at port, there

Table 2. Harmonic Load Flow Analysis Report - Sailing Condition, No Harmonic Filter

\begin{tabular}{|c|c|c|c|}
\hline \multicolumn{4}{|c|}{ VTHD (Total Harmonic Distortion) Report - No Filter } \\
\hline \multirow{2}{*}{\multicolumn{2}{|c|}{ Bus }} & \multirow{2}{*}{\multicolumn{2}{|c|}{$\begin{array}{c}\text { Voltage } \\
\text { Distortion }\end{array}$}} \\
\hline & & & \\
\hline \multirow[b]{2}{*}{ ID } & \multirow[b]{2}{*}{ kV } & Fund. & VTHD \\
\hline & & $\%$ & $\%$ \\
\hline Bus Bar 1 & 0.380 & 100.00 & 6.18 \\
\hline Bus Bar II & 0.380 & 100.00 & 6.18 \\
\hline Bus5 & 0.380 & 99.86 & 6.18 \\
\hline Bus10 & 0.380 & 99.97 & 6.18 \\
\hline Bus11 & 0.380 & 99.99 & 6.18 \\
\hline Bus12 & 0.380 & 99.93 & 6.18 \\
\hline Bus13 & 0.220 & 99.71 & 6.10 \\
\hline Bus14 & 0.220 & 99.77 & 6.14 \\
\hline Cable78 & 0.380 & 99.23 & 6.39 \\
\hline
\end{tabular}

Table 1. Harmonic Load Flow Analysis Report - Maneuvering Condition, No Harmonic Filter

\begin{tabular}{|l|c|c|c|}
\hline \multicolumn{1}{|c|}{ VTHD (Total Harmonic Distortion) Report - No Filter } \\
\hline \multicolumn{1}{|c|}{ Bus } & \multicolumn{2}{c|}{ Voltage } \\
\hline & \multicolumn{2}{c|}{ Distortion } \\
\hline ID & kV & Fund. & VTHD \\
\hline Bus Bar 1 & 0.380 & 100.00 & 6.18 \\
\hline Bus Bar II & 0.380 & 100.00 & 6.18 \\
\hline Bus5 & 0.380 & 99.54 & 6.20 \\
\hline Bus10 & 0.380 & 99.98 & 6.17 \\
\hline Bus11 & 0.380 & 99.99 & 6.18 \\
\hline Bus12 & 0.380 & 99.93 & 6.18 \\
\hline Bus13 & 0.220 & 99.71 & 6.10 \\
\hline Bus14 & 0.220 & 99.77 & 6.14 \\
\hline Cable78 & 0.380 & 99.23 & 6.39 \\
\hline Indicates buses with THD (Total Harmonic Distortion) exceeding the limit & \\
\hline
\end{tabular}

After ship electrical network established on ETAP ${ }^{\circledR}$, then harmonic load flow analysis are need to be simulate in all ship operating condition; sailing, maneuvering, cargo handling, and at port. Because in every condition each electrical devices have a specific electric consumption data. To get the harmonic value and where are no harmonic value after run a simulation. This is because the harmonic source of this ship are majorly caused by a variable frequency drive, a device for controlling the speed of 3-phase electrical motor which on cargo handling and at port are not operated. 


\section{B. Modelling Filter}

There are 6 types of harmonic filter that provided by ETAP $^{\circledR}$. But only the single-tuned harmonic filter can be used for specific harmonic orders. This will have an advantage to minimized the harmonic distortion to meet rules standard.
- $\quad$ Capacitor Rated kV, Max. kV, are determined based on electrical network system technical data. This determined value have to be raised due to protect the system from just in case, an overload condition occured. This process are shown in Figure 4.

- Inductor Q Factor, Max. I, are determined based

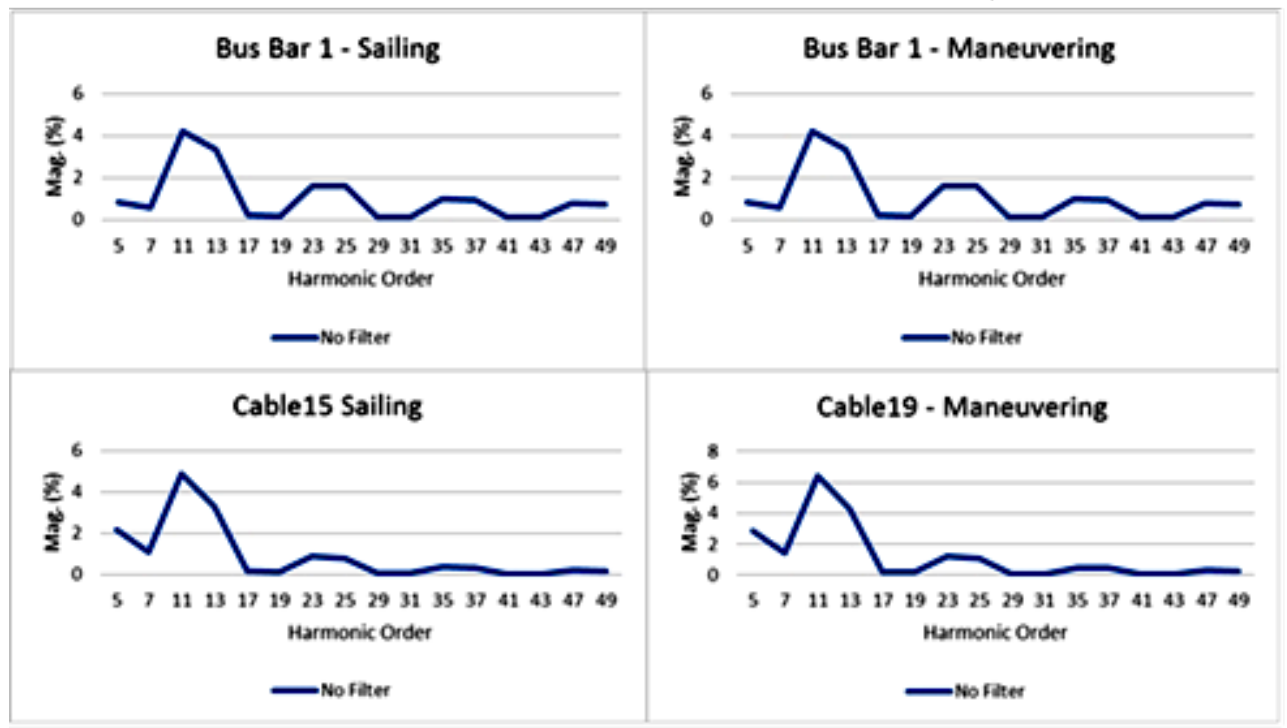

Figure 3. Graphic of Harmonic Value, No Filter Condition

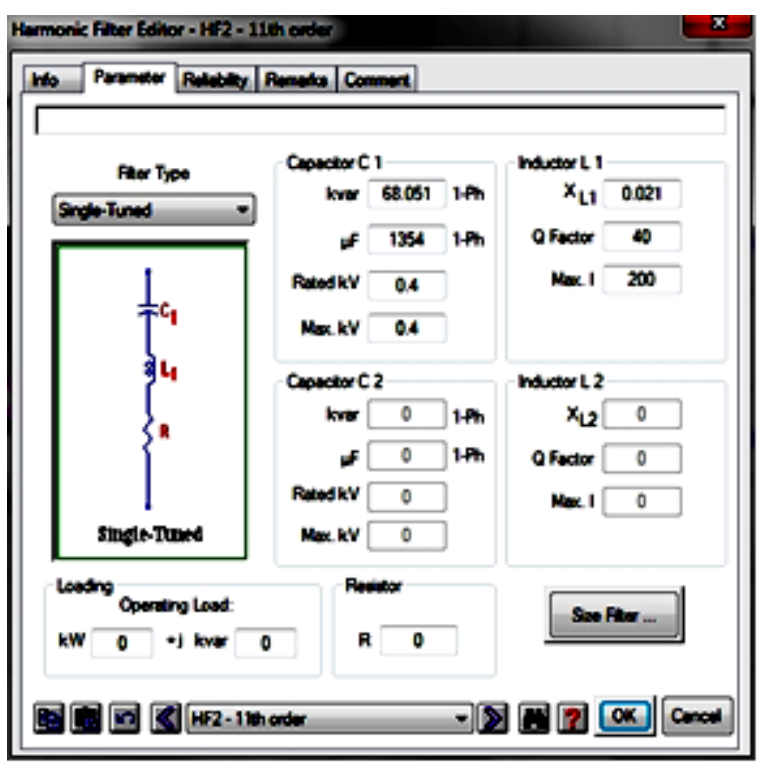

Figure 4. Tuning Single-Tuned Passive Harmonic Filter.

In order to design a single-tuned harmonic filter, then the specific harmonic order need to determined based on the highest harmonic value. Figure 3 are shows some harmonic load flow result that converted into a graphic, Figure 3 already represent all the harmonic value of other devices.

Mag (\%) is represent the harmonic current/voltage magnitudes in Amps/Volts on the fundamental current/voltage base.

Based on the Figure 3 that the harmonic value are majorly all happened on 11th harmonic order. So, the passive filter that will be installed are focused on reducing harmonic on $11^{\text {th }}$ order.

First, the filter must be sized, and here's how to fill the value of each variable; on electrical network system. This determined value can be changed gradually due to get the best result after doing another simulation while a passive filter are connected to the system. This process are shown in Figure 4.

- Capacitor kvar, $\mu \mathrm{F}$, are determined from filter sizing process.

- Inductor XL1 value, are determined from filter sizing process.

To get the value of Capacitor kvar, $\mu \mathrm{F}$, and Inductor XL1 value, it need to fill some value as follows;

- Harmonic Order

- Harmonic Current

- Existing PF

- Desired PF

- Load MVA 
The data above can be obtained from a load flow simulation to get a PF value and a Load MVA value, while harmonic order and harmonic current are
Harmonic current value obtained from harmonic load flow analysis from $11^{\text {th }}$ order that shown in Figure 6.

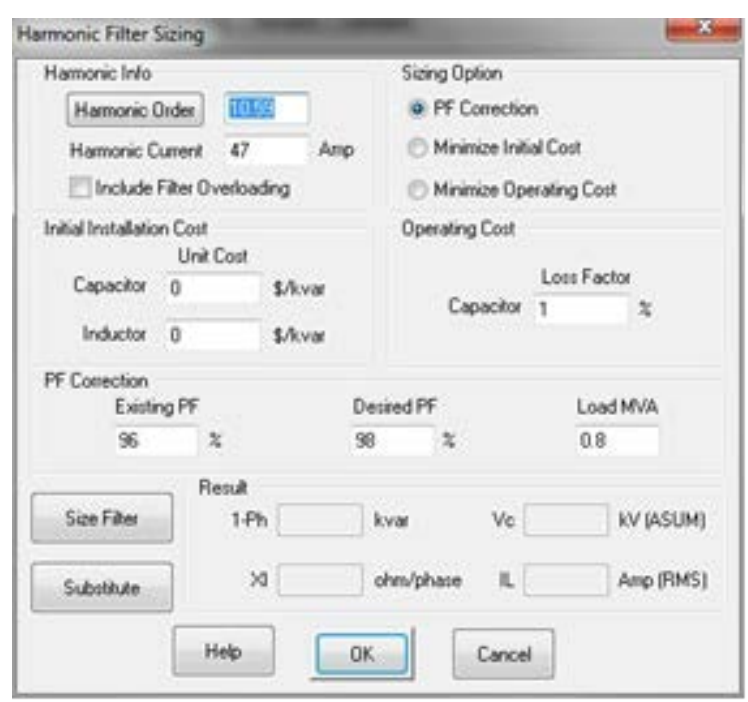

Figure 5. Sizing Single-Tuned Passive Filter

Table 3. Tuning Orders in an applied tuning factor. [8[

\begin{tabular}{|c|c|c|c|c|}
\hline Order & 5 th & 7 th & 9 th & 11 th \\
\hline Tuning & 4.813 & 6.734 & 8.663 & 10.59 \\
\hline Order & 13 th & 15 th & 17 th & 19 th \\
\hline Tuning & 12.51 & 14.44 & 16.36 & 18.29 \\
\hline
\end{tabular}

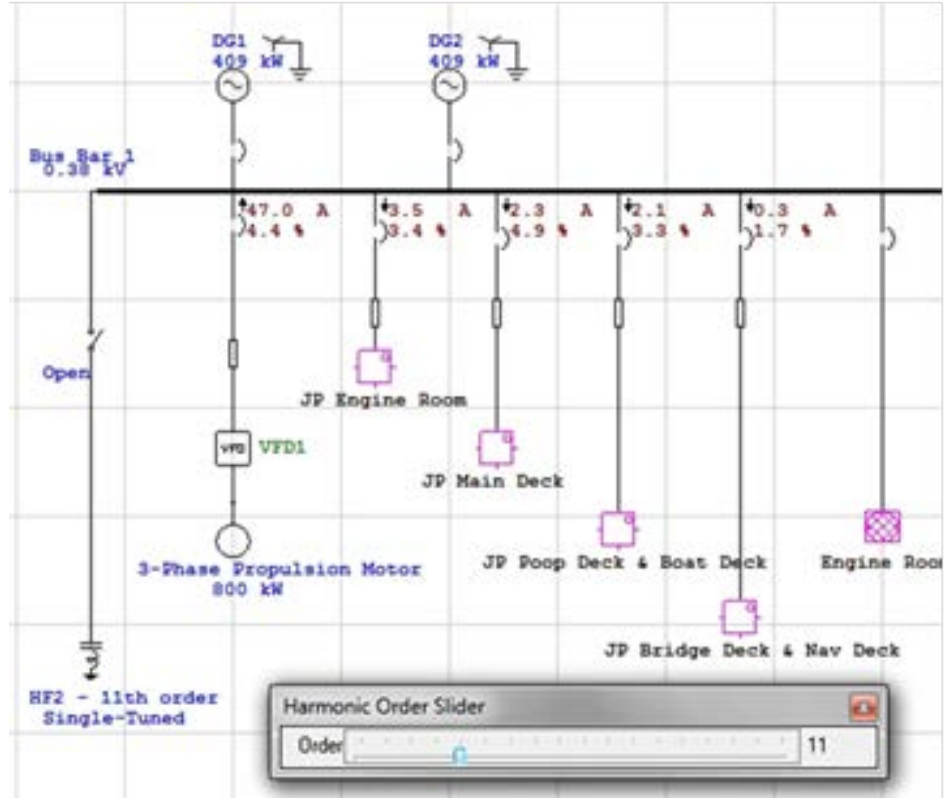

Figure 6. Harmonic Load Flow Analysis

determined by doing a harmonic load flow analysis. This data can be filled in the Harmonic Filter Sizing menu as shown in Figure 5, to open it click Size Filter from dialog box in Figure 4.

Harmonic order are focused on $11^{\text {th }}$ order that mostly have the higher value on all bus and branch. But the harmonic order value were not exactly the value of its harmonic frequency integer (e.g. 5th order harmonic value are not exactly 5). The tuning order to be applied in sizing the single-tuned filter are shown in Table 3.
The result shows the cable that connecting Bus Bar 1 - VFD1 - 3-Phase Propulsion Motor are the highest value of harmonic current on the 11th order. This value then substituted to harmonic current and filter sizing. This value has a same amount on both condition (Sailing and Maneuvering).

Existing PF and Load MVA are obtained from load flow analysis as shown in Figure 7 . The obtained value are taken in the same place (The cable that connecting Bus Bar 1 - VFD1 - 3-Phase Propulsion Motor). This 
value will be substituted to harmonic filter sizing to get a correction so the filter will increase the PF value. reduce the harmonic and distortion. This result will be compared to simulation without installing a passive

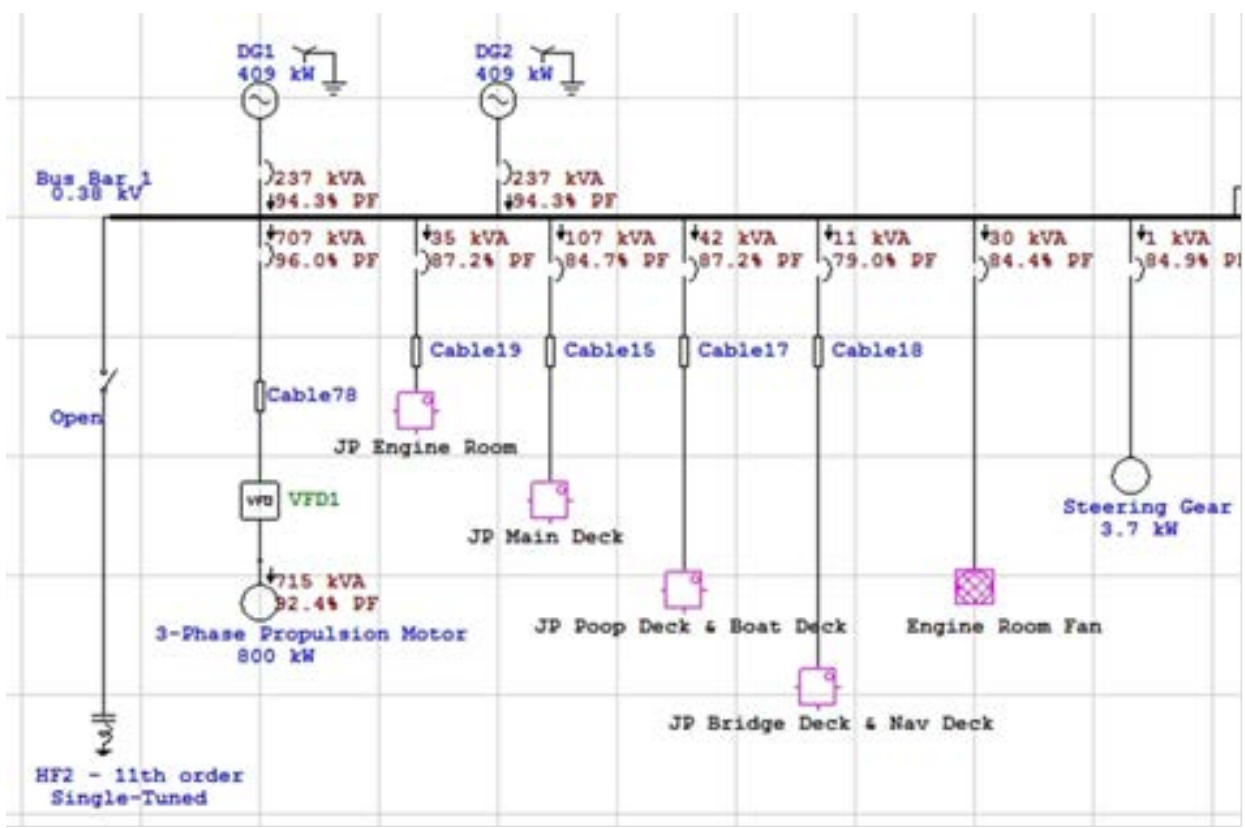

Figure 7. Load Flow Analysis

filter. This is the important point of this thesis, evaluation from the result of installing and simulate IV. RESULT AND DISCUSSION passive filter on the ship electrical network system must

Table 5. Harmonic Load Flow Analysis Report - Sailing Condition, with Passive Filter

\section{VTHD (Total Harmonic Distortion) Report - Passive Filter}

\begin{tabular}{l|c|c|c|}
\multicolumn{1}{|c|}{ Bus } & \multicolumn{2}{c|}{ Voltage } \\
\hline & & \multicolumn{2}{c|}{ Distortion } \\
\hline \multicolumn{1}{|c|}{ ID } & kV & Fund. & VTHD \\
\hline Cable78 & 0.380 & 99.23 & $\%$ \\
\hline Indicates buses with THD (Total Harmonic Distortion) exceeding the limit \\
\hline
\end{tabular}

Table 4. Harmonic Load Flow Analysis - Maneuvering Condition, with Passive Filter

\begin{tabular}{|c|c|c|c|}
\hline \multicolumn{4}{|c|}{ VTHD (Total Harmonic Distortion) Report - Passive Filter } \\
\hline \multirow{2}{*}{\multicolumn{2}{|c|}{ Bus }} & \multirow{2}{*}{\multicolumn{2}{|c|}{$\begin{array}{l}\text { Voltage } \\
\text { Distortion }\end{array}$}} \\
\hline & & & \\
\hline \multirow{2}{*}{ ID } & \multirow{2}{*}{$\mathrm{kV}$} & Fund. & VTHD \\
\hline & & $\%$ & $\%$ \\
\hline Cable78 & 0.380 & 99.23 & 2.72 \\
\hline
\end{tabular}

After modelling filter, the ship electrical network system is already fitted with a passive filter that will be can reduce the harmonic and distortion on the system, and harmonic value shall not exceed 5\% 6 complying with rules and standards.

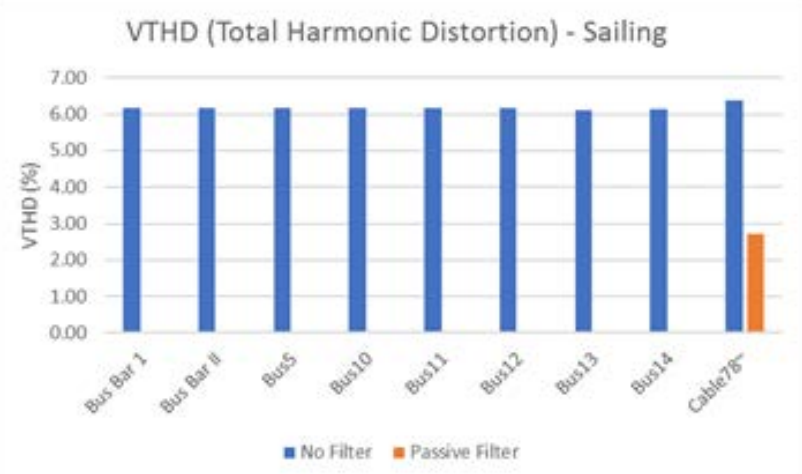

Figure 8. Harmonic Load Flow Analysis Report Chart - Sailing Condition 


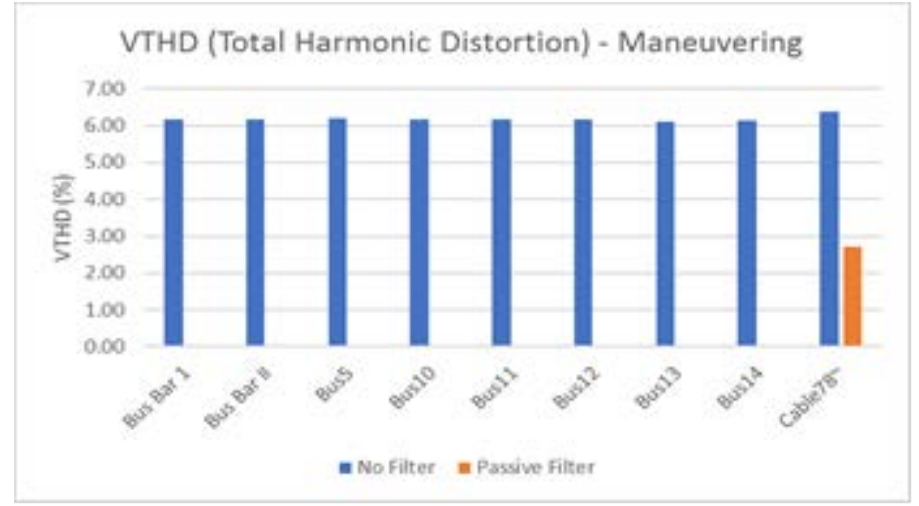

Figure 9. Harmonic Load Flow Analysis Report Chart - Maneuvering Condition

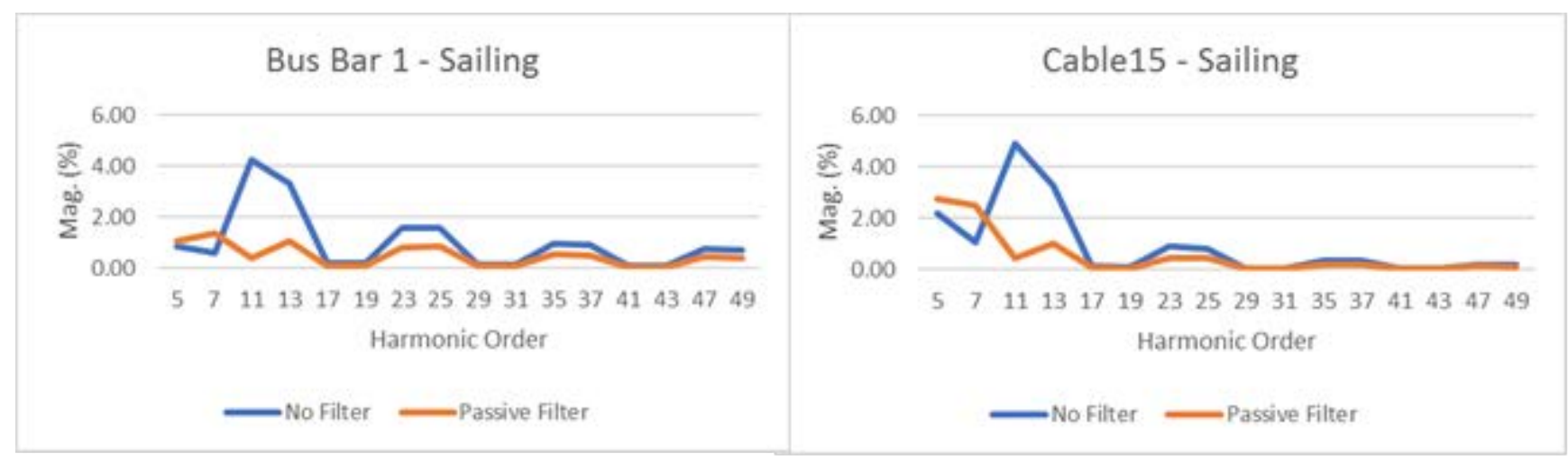

Figure 10. Bus Bar 1 and Cable15 Harmonic Value Comparison - Sailing Condition

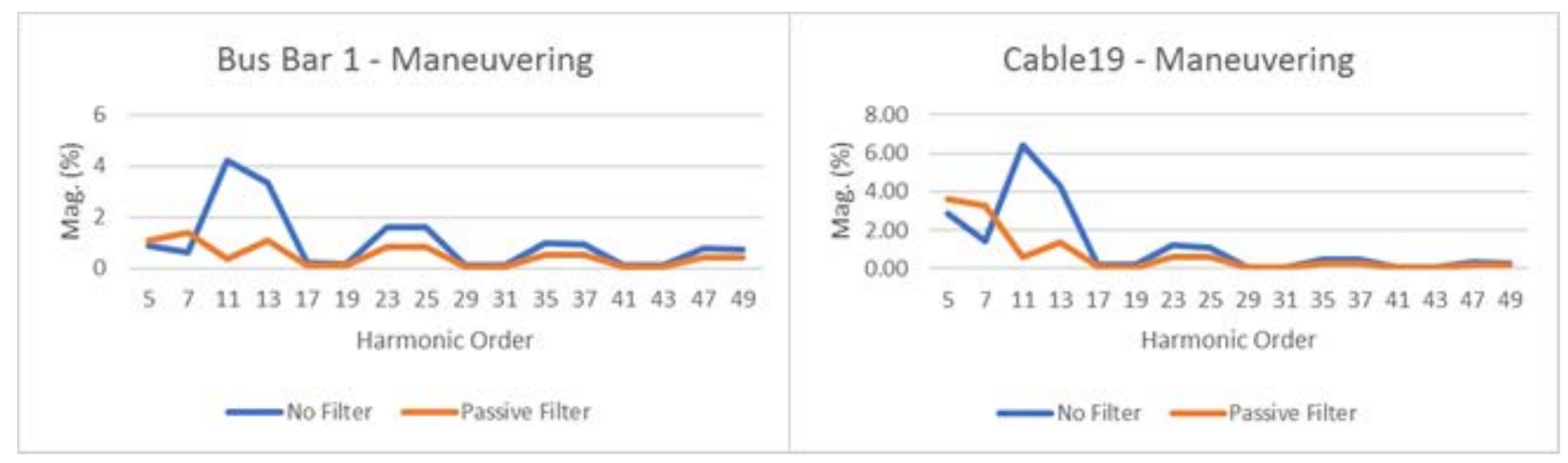

Figure 11. Harmonic Load Flow Analysis Report Chart - Maneuvering Condition

Table 4 and Table 5 are the VTHD report of simulation with passive filter installed. Then, Figure 8, and Figure 9 are some graphs that comparing VTHD value between no filter condition and with passive filter condition.

In Figure 10 and Figure 11 are graphs that represent harmonic value from other devices, cable comparison are taken from the highest Magnitude result.

Both from sailing and maneuvering condition the VTHD value are reduced and mostly the VTHD value are disappear. But only Cable78 that has still VTHD value, this value are shown on Figure 8 and Figure 9. 


\section{CONCLUSION}

There is no harmonic during the cargo handling and at port condition. This is because the harmonic source of this ship is majorly caused by a variable frequency drive, a device for controlling the speed of 3-phase electrical motor which on cargo handling and at port are not operated.

Implementation of Passive Harmonic Filter is very useful to reduce both current and voltage harmonic distortion. Passive harmonic filter can reduce the VTHD value by reducing a specific harmonic order and the impact from reducing specific harmonic order can reduce the other harmonic order.

VTHD value after applying a designed passive harmonic filter are comply with the DNV GL Rules that the total voltage harmonic distortion shall not exceed $5 \%$. Besides that, passive harmonic filter also can gain higher power factor (PF) value.

From both condition, the Mag. value are almost having same value. Both condition also have a similarity that 11th order is reduced on all device.

\section{ACKNOWLEDGEMENT}

This research was supported by Institut Teknologi Sepuluh Nopember, Faculty of Ocean Technology, Marine Engineering Departement. I also would like to acknowledge my supervisor Prof. Semin for his supporting in this paper. I also thanks to my undergraduate student, Faisal M Satrio, for providing the data of this resesrch . Last but not least, I have to express my appreciation to head of Marine Engineering Departement for sharing his pearls of wisdom with me during this research.

\section{REFERENCES}

[1] I. C. Evans, A. H. Hoevenaars, P.Eng, Member, IEEE. 2007. Meeting Harmonic Limits on Marine Vessels.

[2] Alexander Kusko, Marc T. Thompson. POWER QUALITY in ELECTRICAL SYSTEMS. McGraw Hill Professional, 2007. New York, NY, United States.

[3] Abdelhay A. Sallam, Om P. Malik. Electric Distribution Systems. John Wiley and Sons Ltd, 2012, United States.

[4] Dennis T. Hall B.A. (Hons), C. Eng., M.I.E.E., M.I.Mar.E. 1984 PRACTICAL MARINE ELECTRICAL KNOWLEDGE Second Edition, Publication 1999. London. Witherby.

[5] DNV GL SE. Electrical Installations (I-1-3), 2014. Hamburg. DNV GL SE.

[6] ETAP $^{\circledR}$ Software Version 12.6.0

[7] Suryono, Sutedjo, M. Zaenal Efendi, Andrias Ade, Sigit Prasetya. Filter Pasif Untuk Mereduksi dan Memanfaatkan Harmonisa Ke-5 dan 7 pada Beban Konverter 6 Pulsa Sebagai Sumber Energi Dengan Menggunakan Full Bridge DC-DC Converter dan Inverter. Teknik Elektro Industri, Politeknik Elektronika Negeri Surabaya. Surabaya.

[8] Young-Sik Cho \& Hanju Cha (2011), Single-tuned Passive Harmonic Filter Design Considering Variances of Tuning and Quality Factor, Journal of International Council on Electrical Engineering, 1:1, 7-13, DOI: 10.5370/JICEE.2011.1.1.007 